\title{
Universal organic fertilizers "EldORost" based on humic substances
}

\author{
Zhilkibayev O.T. ${ }^{1}$, Shoinbekova S.S. ${ }^{1}$, Sarsenbaeva G.B. ${ }^{2}$, Aitbayev T.E. ${ }^{3}$, Tukenova Z.A. ${ }^{4}$ \\ ${ }^{1} \mathrm{Al}$-Farabi Kazakh National University, Almaty, Kazakhstan, zhilkibaevoral@mail.ru \\ ${ }^{2}$ Kazakh Research Institute of Plant Protection and Quarantine named after Zh. Zhiyembaev, \\ Almaty, Kazakhstan \\ ${ }^{3}$ Kazakh National Agrarian University, Almaty, Kazakhstan \\ ${ }^{4}$ Kazakh Research Institute of Soil Science and Agrochemistry named after U.U.Uspanov, Almaty, \\ Kazakhstan
}

Keywords: humic substances, organic fertilizer, agriculture, crops, yield

doi: 10.36291/HIT.2019.zhilkibayev.130

Seventy percent of Kazakhstan land is subject to desertification. Today some 14 mil ha out of 182 mil ha of Kazakhstan pasture lands are completely non-usable, and the total degradation area exceeds 50 mil ha, which is explained by intensive and very intensive desertification. One of the most efficient methods used to increase soil fertility and crop yield is the use of organic fertilizers. They help increasing the content of humus in soil, soil structure and avoiding many adverse consequences caused by the use of chemicals. In general, environmental balance cannot be maintained without the use of organic fertilizers for farming purposes. Therefore, development of new high-efficiency and low-cost multipurpose organic fertilizers with complex features (regulating, antistress, immunestimulating, moisture-retaining, etc.) on the basis of humic acids becomes very urgent since the need in high-efficiency phytoregulators is growing day in and day out. The purpose of this work is the creation and introduction of a new domestic integrated highperformance organic fertilizer for modern technologies to restore soil fertility, forests, reduce land degradation in arid areas of Kazakhstan and increase the yield of agricultural cultures. We have produced an innovative domestic plant growth regulator from highly oxidized brown coal and lowland peat by extraction using alkali solutions adding a set of amino acids, natural phytohormones and micro- and macroelements. The distinguishing feature and scientific novelty of the proposed project as compared to the traditional ones is the use of natural amino acids, phytoharmones extracted from vegetable raw materials and addition of micro- and macroelements in certain proportions. In-depth laboratory and demonstration field (microplot) comparative tests on cereals, vegetables and other crops demonstrated a high efficiency of the new domestic multipurpose organic plant growth regulator.

"EldoRost" is a natural regulator of plant growth and development and intended for all types of crops in any soil and climatic zones. It promotes the cultivation of environmentally friendly agricultural products and reducing the content of heavy metals, radionuclides and nitrates in products. It is allowed to produce better and more environmentally pure products (with a high content of carbohydrates, proteins, lipids and other valuable substances). The national universal organic plant growth regulator is a natural product what has valuable antioxidant properties. It is actively involved in the neutralization and elimination of toxins.

The study the effect of a new organic fertilizer codenamed EldORost on sowing qualities, yield, and also on the fungal and bacterial microflora of grain seeds (wheat, rice), vegetables (potatoes, carrots, cabbage, cucumbers, tomato), soybeans and fodder crops (Sudanese grass) were conducted in laboratory and field conditions. The new product (growth stimulator) "EldoRost" showed a higher stimulating efficacy in all cultures in comparison with the standard product.

The organic product "EldOrost" increases the crops of the studied plants by $10-50 \%$, increases the root system, enhances the immunity and water-holding capacity of the soil, and accelerates the synthesis of chlorophyll and the maturation of the crop by 10-12 days. 